\title{
When is Scientific Dissent Epistemically Inappropriate?
}

\author{
Boaz Miller*† \\ Published in Philosophy of Science 88(5): 918-928.
}

\begin{abstract}
Normatively inappropriate scientific dissent prevents warranted closure of scientific controversies, and confuses the public about the state of policy-relevant science, such as anthropogenic climate change. Against recent criticism by de MeloMartín and Intemann of the viability of any conception of normatively inappropriate dissent, I identify three conditions for normatively inappropriate dissent : its generation process is politically illegitimate; it imposes an unjust distribution of inductive risks; it adopts evidential thresholds outside an accepted range. I supplement these conditions with an inference-to-the-best-explanation account of knowledge-based consensus and dissent to allow policy makers to reliably identify unreliable scientific dissent.
\end{abstract}

\section{Introduction}

Scientific dissent plays an indispensable role in the growth of scientific knowledge. From Copernicus' heliocentric planetary model, through Marshall and Warren's bacterial theory of peptic ulcers, to Shechtman's theory of quasiperiodic crystal, a marginal dissent view may eventually prevail and become the new consensus. Even when they do not eventually prevail, dissenting views may expose weaknesses in accepted theories and help researchers strengthen them.

Some dissent, however, such as the prolonged dissent about the harmful effects of smoking, is epistemically harmful. According to de Melo-Martín and Intemann, normatively inappropriate dissent (NID) is dissent that "fails to yield any of the epistemic benefits that make even false dissent valuable" $(2018,16)$. (The term "normative" here refers only to epistemic normativity, rather than moral or prudential.) NID hinders the growth of scientific knowledge by preventing warranted closure of scientific controversies, and by leading community research and argumentation efforts astray in unfruitful directions. NID also confuses the public and decision makers about policy-relevant science, such as the theory of anthropogenic climate change. ${ }^{1}$

According to de Melo-Martín and Intemann, a philosophically satisfying characterization of NID "must provide predictive criteria that can reliably identify NID—that is,

\footnotetext{
* To contact the author, please write to: Department of Management Information Systems, Zefat Academic College, 11 Jerusalem St., 1320611 Safed, Israel; e-mail: boaz.m@zefat.ac.il.

† This paper was written with the support of the ISF Grant 650/18 for the Project "Skepticism about Testimony" (PIs: Arnon Keren and Boaz Miller). I thank Kristen Intemann, Inmaculada de Melo-Martín, and David Kovacs for helpful feedback.

${ }^{1}$ Consensus does not mean complete unanimity. For a discussion of the minimal level of agreement that needs to obtain in an epistemic community for a consensus to exist, see Miller (2013, 1300-1303) and Dang (2019). Dissent may also come in different degrees and flavors; see Delborne (2016).
} 
it must be able to identify NID as such when the dissent in question is in fact normatively inappropriate and be able to exclude scientific dissent that is actually legitimate [...] a primary goal of identifying NID is that doing so can allow us to put strategies in place to prevent or address the adverse consequences NID can have" (2018, 8-9).

de Melo-Martín and Intemann argue that there is currently no satisfying characterization of NID. Particularly, so they argue, Biddle and Leuschner's (2015) inductiverisk account of NID is unsuccessful. In this paper, I develop an account of NID that captures the rationale behind Biddle and Leuschner's account, but overcomes de Melo-Martín and Intemann's criticism. ${ }^{2}$

According to my account, a dissent is normatively inappropriate if any of these three conditions obtain: (1) its generation process is politically illegitimate; (2) it imposes an unjust distribution of inductive risks; (3) it adopts evidential thresholds outside an accepted range. I further argue that supplementing these conditions with an inference-to-the-best-explanation account of knowledge-based consensus and dissent allows policy makers to reliably identify when scientific dissent should not be relied on for making policy decisions.

\section{Biddle and Leuschner's Inductive-Risk Account of NID}

Biddle and Leuschner (2015) provide an inductive-risk account for distinguishing epistemically beneficial dissent from NID. Inductive risk is the risk that stems from making a wrong epistemic judgment, such as accepting a false hypothesis or rejecting a true hypothesis (Douglas 2009, Ch. 5). Drawing on Wilholt (2009), who characterizes conventional scientific epistemic standards, e.g., using a critical $p$ value of five percent, as reflecting conventional trade-offs between inductive risks, Biddle and Leuschner formulate four conditions jointly sufficient for a dissent over a hypothesis $\mathrm{H}$ to be considered NID:

Inductive-Risk

The non-epistemic consequences of wrongly rejecting $\mathrm{H}$ are likely to be severe.

\footnotetext{
${ }^{2}$ Two additional accounts of NID may be identified in the literature. Like de Melo-Martín and Intemann, I think they are both inadequate. One account of NID is provided within Longino's Critical Contextual Empiricism (2002, Ch. 6), according to which a dissent is normatively inappropriate when the dissenters fail to take up criticism of it, and continue to hold the dissent view regardless. As de Melo-Martín and Intemann (2018, Ch. 4) and Fernández Pinto (2014), argue, however, Longino's account of NID faces special difficulties dealing with manufactured uncertainty. Who is to judge whether dissenters fail to follow the norm of uptake of criticism or whether their concerns are genuine? When may a community stop engaging with them and move on? Defending Longino against this anticipated charge, Borgerson $(2011,445)$ argues that if we distinguish the level of certainty required for action from that required for knowledge, interested parties will be less motivated to manufacture uncertainty. In response, I have argued elsewhere that Critical Contextual Empiricism should still be able to determine when closure in an epistemic community is warranted despite incessant criticism (Miller 2015, 118-119). In any case, distinguishing between different levels of certainty by inductive risks is in the spirit of the account I develop in this paper. According to a second suggestion, defended most recently by Oreskes (2019), dissent is normatively inappropriate if the dissenting scientists act in bad faith and have a conflict of interest in that the acceptance of the consensus view may financially hurt them or their industry sponsors. As de Melo-Martín and Intemann (2018, Ch. 3) argue, however, scientists perform research for many psychological reasons, and it is hard to judge what bad faith is. With respect to conflict of interests, Oreskes admits that industry-funded science can still be valuable "so long as the norms of critical interrogation are operating and conflicts of interest are forthrightly disclosed and where necessary addressed" $(2019,66-67)$. But if the criterion for NID is ultimately whether the dissenters follow norms of critical scrutiny or not, then Oreskes' account boils down to Longino's account, which, as argued above, is unsatisfactory.
} 
Standards

Producer-Risks

Different-Parties
The dissenting research that constitutes the objection violates established conventional standards.

The dissenting research involves intolerance for industryproducer risks at the expense of public risks.

Producer risks and public risks fall largely upon different parties.

A paradigmatic case of NID that meets Biddle and Leuschner's criteria is the long-lasting dissent from the mid 1950's to the mid 2000's denying a causal connection between smoking and lung cancer, and the harms of passive smoking. This dissent was based on contrarian research and advocacy heavily funded by tobacco companies (Oreskes and Conway 2010). The consequences of this prolonged dissent were illness and death to smokers and people in their close vicinity (conforming to Inductive-Risk). It relied on dubious scientific standards (conforming to Standards). It brought about large profits to tobacco companies at the expense of public health (conforming to Producer-Risks). And the public, rather than tobacco companies, carried most of the burden of these expenses (conforming to Different-Parties).

\section{The Political-Legitimacy and Fairness Conditions for NID}

de Melo-Martín and Intemann make a twofold criticism of Biddle and Leuschner's inductiverisk account of NID. First, they argue that conditions Producer-Risks and Different-Parties that address the distribution of inductive risks are inadequate because some clear cases of NID fail to meet them. Both the dissent that denies that the HIV virus causes AIDS and the dissent that questions the safety of childhood vaccines do not involve intolerance for producer risks at the expense of public risks. In these cases, the dissent goes against the financial interests of drug companies that produce vaccines and AIDS treatments $(2018,66)$. Even the dissent that denies anthropomorphic climate change, which, so Biddle and Leuschner argue, meets their criteria, does not unambiguously satisfy Producer-Risks. While it goes against the interests of fossil fuel companies, it aligns with the interests of alternative energy companies (de Melo-Martín and Intemann 2018, 70). Rajendra Pachauri, the chair of the IPCC from 2002 to 2015, was the director of such company (de Melo-Martín and Intemann 2018, 37). Strictly speaking, these examples do not refute Biddle and Leuschner's account, because it specifies sufficient, rather than necessary conditions for NID. But its failure to capture clear cases of NID, including one that Biddle and Leuschner take their account to capture, significantly hinders its usefulness.

Indeed, whether a dissent is intolerant to producer risks depends on whether the producers produce a problem or a solution. While conditions Producer-Risks and DifferentParties arguably fail, the rationale behind them is still sound. They are meant to prevent an unjust, unfair, or illegitimate weighing or distribution of inductive risks that would stem from accepting the dissent view. I therefore suggest instead the following two conditions which, if a dissent fails to meet, would make it an NID: 
Political-Legitimacy The dissent view has been generated, and adopted as a basis for public action-it if has been adopted-by a politically legitimate knowledge-producing and stabilizing process.

Fairness

The inductive risks that would stem from accepting or adopting the dissent, and the respective harms and benefits that they entail, would be fairly and justly distributed among relevant members of, or groups in society.

These two conditions ensure that both the process and outcome of trading off inductive risks against each other are legitimate. With respect to Political-Legitimacy, the process in question in not only the internal scientific process of research and validation, but also the external process of considering certain claims as a basis for public action. Empirical STS research shows that the stabilization and acceptance or rejection of knowledge claims in policy contexts depends not only on their epistemic validity, narrowly construed, but also on the perceived political legitimacy of the process of their consideration. Which processes are regarded as politically legitimate greatly varies from one political culture to another (Jasanoff 2012). The Political-Legitimacy condition turns this empirical insight into a normative requirement. It would impose restrictions on the process, such as a prohibition on massive lobbying, and adequate public and stakeholder representation (Brown 2009; Rolin 2009).

The Fairness condition ensures that the outcome of the process is just, for example, that disempowered populations would not unjustly suffer the consequences of an error in the dissent view. Unlike Biddle and Leuschner, I do not provide an account of which processes are politically legitimate and which distributions of risk are just. The answer to these questions greatly depends on the particularities of the case and the relevant stakeholders. However, what distribution of inductive risks is just, as opposed to what the inductive risks are, is neither a scientific question nor a question in philosophy of science. ${ }^{3}$ Rather, it is a public ethics question that can be fruitfully debated by ethicists and political philosophers, and resolved in the usual ways political issues are resolved.

It might be objected that the fact that a dissent view unjustly aligns, for example, with the interests of big corporations, or unjustly imposes unfair risks on vulnerable groups does not necessarily mean that the view is false. Hence, pursuing it might have epistemic benefits, and a dissent over it is not NID. A large body of philosophical literature today, however, argues that scientific knowledge is not value free (Douglas 2000; 2009; Elliott 2017; Hicks et al. 2020; Intemann and de Melo-Martín 2010). This claim applies both to applied and basic science. Examples of inductive risks involved in basic science are damaging a researcher's or a journal's reputation, exhausting a pool of reviewers due to over-checking, or losing a priority race (Magnus 2018; Miller 2014b).

Taking seriously the value-ladenness of scientific knowledge means that scientific knowledge claims "reflect the various trade-offs between values that were made in the process of inquiry leading to them," and the appeal to social values "is necessary for achieving scientific objectivity because only it offers a non-arbitrary, principled, and relevant way to decide the various dilemmas that arise during inquiry and influence its outcomes (Miller 2014b, 260). Put differently, the accepted truth value of scientific knowledge claims, including dissent claims, is

\footnotetext{
${ }^{3}$ But a related question of what roles for values in science are legitimate and positive is within the domain of philosophy of science. See Fernández Pinto and Hicks (2019) for an account of a legitimate and positive role for values in regulatory science, and Brown (2020) for an ambitious account for science in general.
} 
entangled with the value judgments that were made in the process of research that produced them. If these value judgements are flawed, so are the knowledge claims.

It might be further objected that imposing unjust risks is not logically tied with an epistemically deficient research program. For example, a James-Bond style evil genius may threaten to destroy the northern hemisphere if the bacterial theory of disease is accepted. Accepting the theory in this case would entail unjust risk for the population of the northern hemisphere, although the theory is epistemically sound. Against this, I argue that the risk in this case does not genuinely stem from the theory (we can replace the theory in this example with any other theory), and it would be hard to find a case like this where the risk is a genuine consequence of accepting the theory in question. While such objections can be devastating for some arguments in analytic epistemology, in the present more realistic context, they carry little force.

\section{The Workable-Evidential-Thresholds Condition for NID}

de Melo-Martín and Intemann's second line of criticism against Biddle and Leuschner's account of NID focuses on the condition Standards. I agree that Standards is problematic, but for reasons different from de Melo-Martín and Intemann's. de Melo-Martín and Intemann understand the term "conventional standards" as referring to accepted methodological rules. They argue that breaching conventional standards cannot always be used for identifying NID because sometimes, the disagreement between the dissenters and consensus supporters is whether a methodological rule has been used correctly or breached. For example, where one groups sees signal, another group sees noise. They may also disagree about the relative weight that should be assigned to different accepted epistemic values (de Melo-Martín and Intemann 2018, 68-69).

Recall, however, that Biddle and Leuschner employ Wilholt's account of shared standards. Wilholt $(2009,98)$ characterizes shared standards as conventions that impose explicit or implicit constraints on acceptable error probabilities within a research community. They are solutions to a social-epistemic problem of coordination in a community: They allow individual researchers to develop a reliable sense of the dependability of certain kinds of scientific outcomes based only on their knowledge of the procedures, rather than of the person who conducted the studies. Namely, provided that a scientist has adequately followed the relevant conventions, other scientists can reliably estimate the reliability of her reported outcomes without knowing her personally.

Thus, according to Wilholt $(2009,99)$, implicit or explicit infringement of shared standards occurs when values, such as personal, economic, or ideological investments, make scientists lower or raise the evidential thresholds in a way that increases the likelihood of arriving at a preferred result, and violates her community's shared understanding of these thresholds. To the extent such evidential thresholds are fixed, Wilholt's characterization of what constitutes an infringement of shared standards is immune to de Melo-Martín and Intemann's criticism.

In my view, the problem with relying on Wilholt's account of what constitutes an infringement of shared standards for the sake of identifying NID lies elsewhere. As Wilholt notes, social values participate in setting the conventional evidential standards. Different social values in different scientific contexts may participate in raising or lowering conventional threshold values. For example, in significance testing, there is an inherent mathematical tradeoff between minimizing false positives and false negatives. Values influence the balance between false positives and false negatives. The existing scientific standards, which are manifested inter alia in the widespread choice of the five percent significance level, are 
conservative in that they regard false positives as more serious errors than false negatives $(2009,99)$.

The problem with relying on such conventional standards for identifying NID is that the implicit or explicit trade-offs between inductive risks that the accepted conventional standards reflect may not be appropriate in the context of normatively appraising the dissent. In particular, the trade-offs they make between inductive risks may violate the Fairness condition. For example, when assessing whether a substance is harmful, the conventional five-percentsignificance-level standard makes a default assumption that a substance is safe, and puts a burden of proof on those who want to claim otherwise. In some contexts, however, we may legitimately want to relax this burden of proof and demand only a seven percent significance level, or even make an opposite default assumption that a substance is unsafe unless proven otherwise.

Wilholt downplays the significance of the specific weighing of inductive risks that a certain conventional standard reflects. For him, any conventional standard can work, as long as it is widely accepted. According to Wilholt, "the standards adopted are arbitrary in the sense that there could have been a different solution to the same coordination problem, but once a specific solution is socially adopted, it is in a certain sense binding" (2009, p. 98). Elsewhere, however, I argue that such standards "are arbitrary only to a certain extent and within a certain range. The conventional critical p-value could have been 6 or 4.6 percent. Such values would also have served as reasonable solutions to the community's coordination problem. A critical pvalue of 45 percent, however, would not have worked, as it would have meant that the community accepted as statistically significant results that were just slightly higher than chance" (Miller 2014a, 75; emphasis added).

That is, conventional evidential thresholds must be within a range that allows scientists to make meaningful knowledge claims. If, for instance, they do not allow scientists to distinguish signal from noise or genuine events from chance events, they are not up to their task. Only within this range, may evidential thresholds be adjusted by values to reflect different trade-offs between inductive risks.

In addition, the evidential standards should not be set in a way that prevents or makes it very unlikely to reach a certain outcome. For example, in 2001, an industry-employed researcher performed an experiment on corn that was genetically modified to contain a toxin for combating root worms. After eight days of experiment, almost $100 \%$ of ladybugs that ate the corn died. In a subsequent experiment, the researcher conveniently stopped recording data after seven days, and determined that the corn was safe for ladybugs (Biddle 2014, 18). Generally speaking, stopping a study as soon as it shows desirable results or just before it would show undesirable results is illegitimate.

I therefore suggest the following condition, which if a dissent violates, would make it an NID:

Workable-Evidential-Thresholds The dissent adopts evidential thresholds within a range which allows researchers to make meaningful knowledge claims, and which is not knowingly likely to rule out a priori the attainment of certain empirical results.

\section{Conflicting Predictions of Risk and Inference to the Best Explanation}

So far I have formulated three conditions for identifying NID: Political-Legitimacy, Fairness, and Workable-Evidential-Thresholds. I have argued that these conditions capture the rationale behind Biddle and Leuschner's inductive-risk account of NID, which is to exclude research that 
imposes unfair risks or violates accepted epistemic standards, while avoiding Melo-Martín and Intemann's criticism of it.

There is, however, a further difficulty with both Biddle and Leuschner's account of NID and mine, which goes as follows. In the cases discussed so far, the consequences of error in either the consensus theory or the dissent theory were not themselves in dispute between the dissenters and consensus supporters. In some cases, however, they are. For example, according to HIV deniers, AIDS symptoms, which the mainstream medical community attributes to the HIV virus, are actually caused by the very treatments that are given to AIDS patients. Unfortunately, the dissent view was adopted as a basis for public health policy by former South African President, Thabo Mbeki. Obviously, HIV-deniers and the mainstream medial consensus would differ on how apply the Fairness condition. The mainstream medical community would regard not treating AIDS patients as imposing an unfair risk on them, while the dissenters would regard treating them for AIDS as imposing an unfair risk on them. How should we arbitrate such cases?

I suggest that when there are conflicting predictions of risk between dissenters and consensus supporters, for the sake of applying the Fairness condition, we should adopt the view that is more likely to be knowledge based. According to my previously published account of knowledge-based consensus (Miller 2013; 2016), a consensus is knowledge based when knowledge is the best explanation thereof. There are four types of consensus, three of which are not knowledge based and one is. The first is a non-cognitive consensus, which aims at promoting non-epistemic aims. The second is a "vertically-lucky" consensus. This is an agreement that happens to be correct, but could have easily been wrong. The third is an epistemically unfortunate consensus, in which parties to the consensus have the bad luck of being systematically or deliberately mislead or biased. When a consensus belongs to none of these three types, it is likely to be knowledge-based.

When we can eliminate non-epistemic factors, veritic epistemic luck, and epistemic misfortune as the best explanations of a consensus, knowledge remains its best explanation. I identify three conditions for knowledge being the best explanation of a consensus: (1) social calibration: researchers give the same meaning to the same terms and share the same fundamental background assumptions; (2) apparent consilience of evidence: the consensus seems to be built on an array of evidence that is drawn from a variety of techniques and methods; (3) social diversity: the consensus is shared by men and women, researchers from the private and public sectors, liberals and conservatives, etc. ${ }^{4}$

In a recent paper (Miller 2019, 234), I explain how my account of knowledge-based consensus can be expanded to deal with dissent as well. If knowledge remains the best explanation of a consensus excluding a dissent, and the dissent is best explained by nonepistemic factors, such as financial interests or personal investment, then we may still legitimately infer that the consensus excluding the dissent is knowledge-based .

In the case of AIDS, the medical consensus that the HIV virus causes AIDS arguably satisfies the three conditions for knowledge-based consensus, hence knowledge is its best explanation. By contrast, the dissent is arguably best explained by the personal investment of the few dissenting scientists, primarily molecular biologist Peter H. Duesberg, in the theory and by the external political support they have managed gain. ${ }^{5}$ Thus, a correct application of the

\footnotetext{
${ }^{4}$ As Dellsén (2018) argues, complete agreement with no dissent whatsoever is suspicious, because its best explanation is not knowledge, but some form of coercion or group-think.

${ }^{5}$ Space limitations prevent me from presenting here the empirical evidence for this claim.
} 
Fairness condition in this case would be that denying AIDS treatment exposes AIDS patients to unfair risks, rather than administrating the treatment to them.

It might be objected that this suggestion unjustly discriminates against dissenting scientists just because they are dissenting. For example, Copernicus was also dissenter, but his view eventually prevailed. Against this, I argue that my account gives the right verdict on the Copernicus case (in any case, the Copernicus example does not meet the previous conditions for NID). First, it would be Whiggishly wrong to say that Copernicus was right. A central hypothesis that Copernicus made, namely, that the sun, rather than earth, was the center of the planetary system survived, but the rest of his theory, including the hypothesis that planets move in uniform circular motion and the system of epicycles he developed, were proven wrong. Second, as it is well known, Copernicus did not have a theory of a moving earth, thus he could not explain why the earth appeared stationary. Last, he could not explain the lack of stellar parallax predicted by his theory. Arguably, he speculated correctly, but did not know that the earth rotated around the sun. Knowledge was not the best explanation of his belief. The consensus of his time was arguably also not knowledge-based because it was maintained by the Church, which blocked alternative views from being explored. The conclusion that neither the consensus nor the dissent in this case were knowledge base is arguably the right one.

\section{Conclusion}

I have defended an inductive-risk account of epistemically inappropriate dissent. I agree with de Melo-Martín and Intemann (2018, Ch. 6), however, that even if my account is successful, targeting an epistemically inappropriate dissent may not always be advisable. A better strategy may be to target the underlying causes that give rise to an epistemically inappropriate dissent in the first place. Targeting these underlying causes, however, is not always practicable, and my account can still, in some cases, help public members and policy makers decide which scientists to trust.

\section{$\underline{\text { References }}$}

Biddle, Justin and Anna Leuschner. 2015. "Climate Skepticism and the Manufacture of Doubt: Can Dissent in Science Be Epistemically Detrimental?" European Journal for Philosophy of Science 5(3): 261-278.

Biddle, Justin. 2014. "Can Patents Prohibit Research? On The Social Epistemology of Patenting and Licensing in Science." Studies in History and Philosophy of Science 45: 14-23.

Borgerson, Kirstin. 2011. Amending and Defending Critical Contextual Empiricism. European Journal for Philosophy of Science 1(3): 435-449.

Brown, Mark B. 2009. Science in Democracy: Expertise, Institutions, and Representation. Cambridge, MA: MIT Press.

Brown, Matthew J. 2020. Science and Moral Imagination: A New Ideal for Values in Science. Pittsburgh: University of Pittsburgh Press.

Dang, Haixin. 2019. “Do Collaborators in Science Need to Agree?” Philosophy of Science 86(5): 1029-1040. 
de Melo-Martín, Inmaculada and Kristen Intemann. 2018. The Fight against Doubt: How to Bridge the Gap between Scientists and the Public. Oxford: OUP.

Delborne, Jason A. 2016. "Suppression and Dissent in Science." In Handbook of Academic Integrity, ed. Tracy Bretag, 943-956. Singapore: Springer.

Dellsén, Finnur. 2018. "When Expert Disagreement Supports the Consensus." Australasian Journal of Philosophy 96(1): 142-156.

Douglas, Heather. 2000. "Inductive Risk and Values in Science." Philosophy of Science 67(4): 559-579.

Douglas, Heather. 2009. Science, Policy, and the Value-Free Ideal. Pittsburgh: University of Pittsburgh Press.

Elliott, Kevin C. 2017. A Tapestry of Values: An Introduction to Values in Science. Oxford: OUP.

Fernández Pinto, Manuela and Daniel J. Hicks. 2019. "Legitimizing Values in Regulatory Science." Environmental Health Perspectives 127(3): 0350011-0350018.

Fernández Pinto, Manuela. 2014. "Philosophy of Science for Globalized Privatization: Uncovering Some Limitations of Critical Contextual Empiricism." Studies in History and Philosophy of Science 47: 10-17.

Hicks, Daniel J., P. D. Magnus, and Jessey Wright. 2020. "Inductive Risk, Science, and Values: A Reply to MacGillivray." Risk Analysis 40(4): 667-673.

Intemann, Kristen and Inmaculada de Melo-Martín. 2010. "Social Values and Scientific Evidence: The Case of the HPV Vaccines." Biology and Philosophy 25(2): 203-213.

Jasanoff, Sheila. 2012. “The Practices of Objectivity in Regulatory Science." In Social Knowledge in the Making, eds. Charles Camic, Neil Gross, and Michèle Lamont, 307-338. Chicago: University of Chicago Press.

Longino, Helen. 2002. The Fate of Knowledge. Princeton: Princeton University Press.

Magnus, P. D. 2018. "Science, Values, and the Priority of Evidence." Logos \& Episteme 9(4): 413-431.

Miller, Boaz. 2013. "When Is Consensus Knowledge Based? Distinguishing Shared Knowledge from Mere Agreement." Synthese 190(7): 1293-1316.

----. 2014a. "Catching the WAVE: The Weight-Adjusting Account of Values and Evidence." Studies in History and Philosophy of Science 47: 69-80.

----. 2014b. “Science, Values, and Pragmatic Encroachment on Knowledge.” European Journal for the Philosophy of Science 4(2): 253-270. 
----. 2015. “'Trust Me - I'm a Public Intellectual': Margaret Atwood's and David Suzuki's Social Epistemologies for Climate Science." In Speaking Power to Truth: Digital Discourse and the Public Intellectual, eds. Michael Keren and Richard Hawkins, 113-128. Athabasca, AB: Athabasca University Press.

----. 2016. "Scientific Consensus and Expert Testimony in Courts: Lessons from the Bendectin Litigation." Foundations of Science 21(1): 15-33.

----. 2019. “The Social Epistemology of Consensus and Dissent.” In The Routledge Companion to Social Epistemology, eds. David Henderson, Peter Graham, Miranda Fricker, and Nikolaj Pedersen, 228-239. New York: Routledge.

Oreskes, Naomi and Erik M. Conway. 2010. Merchants of Doubt: How a Handful of Scientists Obscured the Truth on Issues from Tobacco Smoke to Global Warming. New York: Bloomsbury.

Oreskes, Naomi. 2019. Why Trust Science? Princeton: Princeton University Press.

Rolin Kristina. 2009. "Scientific Knowledge: A Stakeholder Theory." In The Social Sciences and Democracy, ed. Jeroen van Bouwel, 62-80. New York: Palgrave-Macmillan.

Wilholt, Torsten. 2009. "Bias and Values in Scientific Research." Studies in History and Philosophy of Science 40: 92-101. 